\title{
Free carnitine and branched chain amino acids are not good biomarkers in Huntington's disease
}

\section{Carnitina livre e aminoácidos de cadeia ramificada não são bons biomarcadores na doença de Huntington}

\author{
Raphael Machado CASTILHOS 1,14,15, Marina Coutinho AUGUSTIN7,14, José Augusto dos SANTOS7,14, \\ José Luiz PEDROSO ${ }^{9}$, Orlando BARSOTTINI ${ }^{9}$, Roberta SABA ${ }^{9}$, Henrique Ballalai FERRAZ? \\ Fernando Regla VARGAS ${ }^{10,11}$, Gabriel Vasata FURTADO 1,12, Marcia Polese-BONATTO ${ }^{2,13}$, \\ Luiza Paulsen RODRIGUES 3,12, Lucas Schenatto SENA', Carmen Regla VARGAS 2,4,8,13, \\ Maria Luiza SARAIVA-PEREIRA 1,2,3,5,12,13,14, Laura Bannach JARDIM11,6,12,13,14,15, Rede NEUROGENÉTICA ${ }^{16}$
}

\begin{abstract}
Background: Huntington's disease (HD), caused by an expanded CAG repeat at HTT, has no treatment, and biomarkers are needed for future clinical trials. Objective: The objective of this study was to verify if free carnitine and branched chain amino acids levels behave as potential biomarkers in HD. Methods: Symptomatic and asymptomatic HD carriers and controls were recruited. Age, sex, body mass index (BMI), age of onset, disease duration, UHDRS scores, and expanded CAG tract were obtained; valine, leucine, isoleucine, and free carnitine were measured. Baseline and longitudinal analysis were performed. Results: Seventy-four symptomatic carriers, 20 asymptomatic carriers, and 22 non-carriers were included. At baseline, valine levels were reduced in symptomatic and asymptomatic HD carriers when compared to non-carriers. No difference in free carnitine or isoleucine+leucine levels were observed between groups. BMI of symptomatic individuals was lower than those of non-carriers. Valine levels correlated with BMI. Follow-up evaluation was performed in 43 symptomatic individuals. UHDRS total motor score increased 4.8 points/year on average. No significant reductions in BMI or valine were observed, whereas free carnitine and isoleucine+leucine levels increased. Conclusions: Although valine levels were lower in HD carriers and were related to BMI losses observed in pre-symptomatic individuals, none of these metabolites seem to be biomarkers for HD.
\end{abstract}

Keywords: Biomarkers; Amino Acids, Branched-Chain; Carnitine; Huntington Disease; Weight Loss.

\section{RESUMO}

Introdução: A doença de Huntington (DH), causada por uma repetição CAG expandida no HTT, não possui tratamento e biomarcadores são necessários para futuros ensaios clínicos. Objetivo: Nosso objetivo foi verificar se os níveis de carnitina livre e aminoácidos de cadeia ramificada se comportam como potenciais biomarcadores na DH. Métodos: Portadores sintomáticos e assintomáticos e controles foram recrutados. Idade, sexo, índice de massa corporal (IMC), idade de início, duração da doença, escores UHDRS e trato CAG expandido foram

\footnotetext{
1Programa de pós-graduação em Genética e Biologia Molecular, Universidade Federal do Rio Grande do Sul, Porto Alegre RS, Brazil. ${ }^{2}$ Programa de pós-graduação em Bioquímica, Universidade Federal do Rio Grande do Sul, Porto Alegre RS, Brazil.

${ }_{3}^{3}$ Programa de pós-graduação em Biologia Molecular e Celular, Universidade Federal do Rio Grande do Sul, Porto Alegre RS, Brazil.

4Programa de pós-graduação em Ciências Farmacêuticas, Universidade Federal do Rio Grande do Sul, Porto Alegre RS, Brazil.

${ }^{5}$ Departamento de Bioquímica, Universidade Federal do Rio Grande do Sul, Porto Alegre RS, Brazil.

${ }^{6}$ Departamento de Medicina Interna, Universidade Federal do Rio Grande do Sul, Porto Alegre RS, Brazil.

${ }^{7}$ Faculdade de Medicina, Universidade Federal do Rio Grande do Sul, Porto Alegre RS, Brazil.

${ }^{8}$ Faculdade de Farmácia, Universidade Federal do Rio Grande do Sul, Porto Alegre RS, Brazil.

${ }^{9}$ Disciplina de Neurologia Clínica, UNIFESP - Escola Paulista de Medicina, Universidade Federal de São Paulo, São Paulo SP, Brazil.

${ }^{10}$ Hospital Gaffrée e Guinle, Universidade Federal do Estado do Rio de Janeiro, Rio de Janeiro RJ, Brazil.

"Laboratório de Epidemiologia de Malformações Congênitas, Instituto Oswaldo Cruz, Fundação Oswaldo Cruz, Rio de Janeiro, RJ, Rio de Janeiro RJ, Brazil. ${ }^{12}$ Laboratório de Identificação Genética, Centro de Pesquisa Experimental, Hospital de Clínicas de Porto Alegre, Porto Alegre RS, Brazil.

${ }^{13}$ Serviço de Genética Médica, Hospital de Clínicas de Porto Alegre.

${ }^{14}$ Rede Neurogenética, Centro de Pesquisa Clínica, Hospital de Clínicas de Porto Alegre, Porto Alegre, Brazil.

${ }^{15}$ Instituto Nacional de Genética Médica Populacional (INAGEMP), Porto Alegre RS, Brazil.

${ }^{16}$ Rede Neurogenética, Centro de Pesquisa Clínica, Hospital de Clínicas de Porto Alegre, Porto Alegre, Brazil.

Raphael Machado CASTILHOS (iD https://orcid.org/0000-0002-1905-2084; José Luiz PEDROSO (ID https://orcid.org/0000-0002-1672-8894; Orlando BARSOTTINI ID https://orcid.org/0000-0002-0107-0831; Roberta SABA iD https://orcid.org/0000-0002-6556-8145;

Henrique Ballalai FERRAZ (iD https://orcid.org/0000-0002-3821-1407; Gabriel Vasata FURTADO (iD) https://orcid.org/0000-0002-7063-4987; Maria Luiza SARAIVA-PEREIRA (iD) https://orcid.org/0000-0003-3905-9563; Laura Bannach JARDIM (iD) https://orcid.org/0000-0001-6907-5068

Correspondence: Laura Bannach Jardim; Hospital de Clínicas de Porto Alegre; Rua Ramiro Barcelos, 2350; 90035-903 Porto Alegre RS, Brazil;

E-mail: ljardim@hcpa.edu.br

Conflict of interest: The authors declare no conflict of interest.
}

Received on June $7^{\text {th }}, 2019$; Received in its final form on August 28 $8^{\text {th }}, 2019$; Accepted on September $17^{\text {th }}, 2019$. 
obtidos; valina, leucina, isoleucina e carnitina livre foram medidas. Foram realizadas análises basal e longitudinal. Resultados: Setenta e quatro portadores sintomáticos, 20 portadores assintomáticos e 22 não portadores foram incluídos. No início do estudo, os níveis de valina estavam reduzidos em portadores de DH sintomáticos e assintomáticos quando comparados aos não portadores. Não foram observadas diferenças nos níveis de carnitina livre ou isoleucina + leucina entre os grupos. O IMC dos indivíduos sintomáticos foi menor que o dos não portadores. Níveis de valina correlacionaram-se com o IMC. Avaliação de acompanhamento foi realizada em 43 indivíduos sintomáticos. A pontuação do escore motor total da UHDRS aumentou 4,8 pontos/ano em média. Não foram observadas reduções significativas no IMC ou na valina, enquanto os níveis de carnitina livre e isoleucina+leucina aumentaram. Conclusões: Embora os níveis de valina tenham sido menores nos portadores de DH e estivessem relacionados às perdas de IMC observadas em indivíduos pré-sintomáticos, nenhum desses metabólitos parece ser biomarcador para a $\mathrm{DH}$.

Palavras-chave: Biomarcadores; Aminoácidos de Cadeia Ramificada; Carnitina; Doença de Huntington; Perda de Peso.

Huntington's disease (HD) is an autosomal dominant neurodegenerative disorder, caused by an expanded CAG tract at $H T T^{1}$. HD is characterized by chorea, behavioral and cognitive deterioration, and a progressive course. Identifying biomarkers of HD progression is critical in the context of developing disease-modifying drugs, especially if they are sensitive and accurate enough to detect early stages of the disease. Among other candidates, energy deficiency and changes in metabolism were proposed, considering they might have a potential role in the complex pathophysiological mechanisms underlying neurological deterioration in $\mathrm{HD}^{2}$.

Carnitine is a metabolite derived from amino acids and plays a critical role in energy production, transporting longchain fatty acids into the mitochondria, and toxic compounds out of this organelle ${ }^{3}$. Decline in mitochondrial function has been associated with aging, as well as with $\mathrm{HD}^{4}$. Carnitine concentration declines with age, reducing the integrity of the mitochondrial membrane ${ }^{3}$; this effect might be potentiated in $\mathrm{HD}^{5}$. Although carnitine does not participate directly on the energy resources used by the central nervous system (CNS), early findings related deficits of this metabolite to HD. Cuturic et al. reported low serum levels of carnitine in 26\% (6/23) institutionalized HD patients 5 .

Branched chain amino acids (BCAAs) - valine, leucine and isoleucine - are essential to promote protein synthesis and turnover, as well as to energetic metabolism. BCAAs participate in mitochondrial intermediary metabolism and have physiological roles in both the immune system and brain functions ${ }^{6}$. Several studies demonstrated that BCAAs plasmatic levels were low in HD patients ${ }^{7-9}$. Underwood et al. performed a chromatographic spectrometry of several metabolites to determine the metabolic profile of HD and found low levels of valine, leucine and isoleucine, both in asymptomatic and symptomatic HD carriers, suggesting a catabolic state early in the disease ${ }^{7}$. Similarly, Mochel et al. found decreased plasmatic levels of valine, leucine and isoleucine in HD symptomatic individuals, compared with controls. BCAAs levels were correlated both with weight loss and disease severity, measured by UHDRS 8 .

Although carnitine and BCAAs were proposed as candidate biomarkers of disease onset (in at-risk individuals) and/or functional and motor progression in HD (in the symptomatic), longitudinal observations for symptomatic and pre-symptomatic phases of the disease are still missing. Our aims were to verify whether free carnitine and BCAAs plasmatic levels were decreased in HD mutation carriers, and whether those levels decreased progressively throughout 12-month follow-up.

\section{METHODS}

\section{Population}

Symptomatic individuals with molecular diagnosis of $\mathrm{HD}$ and their relatives at 50\% risk of developing HD were invited to participate in this study. At-risk relatives who were not previously included in pre-symptomatic testing (PST) were blinded to molecular results; those who decided to receive their results were referred to the PST programs at our institutions.

\section{Procedures}

Baseline observations occurred between June 2014 and December 2015 and included clinical observations and blood collection for metabolic analyses and molecular studies. A second observation was performed 12 months later in symptomatic individuals only, when another blood sample was collected for metabolic analyses.

Age, sex, body mass index (BMI) (weight in kilograms divided by height in square meters), and blood sample collections were obtained from each individual at baseline. Additional data, such as age of onset (AO), disease duration (DD) since the beginning of chorea, and whole Unified Huntington's Disease Rating Scale (UHDRS) were obtained from symptomatic subjects. In symptomatic carriers, BMI, blood collections, and UHDRS were obtained 12 months later. CAG repeated length of normal and expanded HTT alleles were obtained for all individuals, as previously described ${ }^{10}$.

Blood samples were collected in a filter paper for free carnitine and BCAAs analyses. Samples from at-risk individuals were collected only at baseline, whereas samples from symptomatic carriers were collected at both baseline and at 12-month follow-up. Free carnitine and BCAAs were analyzed by liquid chromatography coupled with mass spectrometry (LC/MS/ 
MS), using multiple reaction monitoring (MRM). The individuals were fasting for at least 2 hours by the time of blood collection, done after all clinical evaluations. Results were expressed in $\mu \mathrm{mol} / \mathrm{L}$; levels of isoleucine and leucine were given as a single value (isoleucine+leucine) because our method did not allow the separation of leucine from isoleucine.

\section{Analysis}

Free carnitine and BCAAs (studied as candidates for biomarkers in HD) were the primary endpoints both in the symptomatic (cross-sectional and longitudinal observations) and asymptomatic (cross-sectional) groups. Total Functional Capacity (TFC) and Total Motor Score (TMS) scales were used as gold standards against which candidate biomarkers were compared. CAP (CAG Age product) score, expanded $\mathrm{CAG}, \mathrm{DD}$ and $\mathrm{AO}$ were independent variables that determine disease severity.

All researchers but the principal investigator (PI) (LBJ) were kept blind to the results of molecular testing of at-risk individuals and to the biochemical results of both at-risk and symptomatic individuals. The PI added them to the database at the end of the study duration and turned all data anonymous.

Subjects were divided into three groups: symptomatic carriers, asymptomatic carriers, and related controls. They were then compared in a cross-sectional design. For correlation studies, all expanded CAG tract carriers had their CAP score calculated.
Mean/standard deviation (SD) and median/interquartile range (IQR) were used according to sample distribution; nonparametric/parametric statistical tests were chosen as appropriate. A generalized estimating equation (GEE) model was fitted to estimate the progression of severity scales, BMI, free carnitine and BCAAs in the longitudinal observation of the symptomatic groups. Time was coded as 0 (baseline) or 1 (one year of study). All analyses were carried out using the SPSS 18 statistical software package (SPSS Inc., Chicago, IL). The significance level was 0.05 .

\section{Compliance with Ethics Standards}

An informed consent was obtained from all participants. This study was approved by the Ethics Committee (EC) from our institution (Comitê de Ética em Pesquisa do Hospital de Clínicas de Porto Alegre) and by the EC from Hospital São Paulo (UNIFESP) and Hospital Graffrée e Guinle (UNIRIO).

\section{RESULTS}

\section{Cross-sectional findings: \\ differences between groups}

One hundred and sixteen individuals (of which 68 females) from $69 \mathrm{HD}$ families were included in the present study: 74 were symptomatic expanded CAG tract carriers, 20 were asymptomatic carriers, and 22 were non-carriers (related controls). General characteristics of this cohort are presented in Table 1.

Table 1. General characteristics of groups under study — non-carriers, asymptomatic, and symptomatic carriers.

\begin{tabular}{|c|c|c|c|c|c|}
\hline & All & Non-carriers & $\begin{array}{l}\text { Asymptomatic } \\
\text { carriers }\end{array}$ & $\begin{array}{l}\text { Symptomatic } \\
\text { carriers }\end{array}$ & $\mathrm{p}$-value \\
\hline n (\% Female) & $116(68)$ & $22(15)$ & $20(13)$ & $74(37)$ & $0.216\left(\chi^{2}\right)$ \\
\hline Age (mean $\pm S D)$ & $45.9 \pm 13.1$ & $40.8 \pm 13.7$ & $35.3 \pm 11.3$ & $50.3 \pm 11.2$ & $<0.001$ (Anova) \\
\hline $\begin{array}{l}\mathrm{BMI}\left(\mathrm{kg} / \mathrm{m}^{2}\right)^{\mathrm{a}} \\
\text { median (IQR) } \\
\text { Normal range: 18.5-24.9 }\end{array}$ & $23.4(20.9-26.4)$ & $26.7(22.7-30.35)$ & $23(20.5-26.2)$ & $23.25(20.85-25.2)$ & 0.006 (Kruskal-Wallis) \\
\hline $\begin{array}{l}\text { Free carnitine }(\mu \mathrm{mol} / \mathrm{L}) \\
\text { median (IQR) } \\
\text { Normal range: } 22.2-54\end{array}$ & $30.9(25.55-37.8)$ & $33.5(28.7-40.45)$ & $30.35(26-35.7)$ & $28.7(25.1-38.6)$ & 0.274 (Kruskal-Wallis) \\
\hline $\begin{array}{l}\text { Valine }(\mu \mathrm{mol} / \mathrm{L}) \\
\text { median (IQR) } \\
\text { Normal range: 48.8-141 }\end{array}$ & $112.5(89.8-133)$ & $123(98.65-164.25)$ & $101.25(79.6-123.5)$ & $110(88.4-131)$ & 0.045 (Kruskal-Wallis) \\
\hline $\begin{array}{l}\text { Isoleucine+leucine ( } \mathrm{Hmol} / \mathrm{L}) \\
\text { median }(\mathrm{IQR}) \\
\text { Normal range: } 41.6-110\end{array}$ & $76.7(65.15-91.9)$ & $84.6(67.2-106.25)$ & $75.2(61-91.2)$ & $75.6(63.5-89.3)$ & 0.231 (Kruskal-Wallis) \\
\hline $\begin{array}{l}\text { Expanded CAG } \\
\text { median (IQR) }\end{array}$ & - & - & $43(41.25-44.75)$ & $44(43-46.25)$ & 0.034 (Mann-Whitney) \\
\hline CAP score (mean $\pm S D)$ & - & - & $72.2 \pm 23.3$ & $116 \pm 18$ & $\begin{array}{l}<0.001 \\
\text { (t-test) }\end{array}$ \\
\hline Age at onset (mean $\pm S D$ ) & - & - & - & $41.5 \pm 11.2$ & \\
\hline
\end{tabular}

SD: standard deviation; anumber of individuals who had body mass index (BMI) calculated: symptomatic $(n=70)$, asymptomatic $(n=19)$, non-carriers ( $n=21)$; IQR: interquartile range. 
At baseline, valine levels (median, IQR) were reduced in both asymptomatic carriers (101.2, 79.6-123.5 $\mu \mathrm{mol} / \mathrm{L})$ and HD patients $(110.0,88.4-131.0 \mu \mathrm{mol} / \mathrm{L})$ when compared to non-carriers (123.0, 98.7-164.2 $\mu \mathrm{mol} / \mathrm{L})(\mathrm{p}=0.018$ and $\mathrm{p}=0.042$, Mann-Whitney). No differences in free carnitine or isoleucine+leucine levels were seen between groups (ns, Kruskal-Wallis) (Table 1 and Figure 1). BMI of symptomatic individuals were lower than those of non-carriers $(p=0.005$, Kruskal-Wallis). No difference was found between non-carriers and asymptomatic carriers (ns, Kruskal-Wallis) (Table 1 and Figure 2).

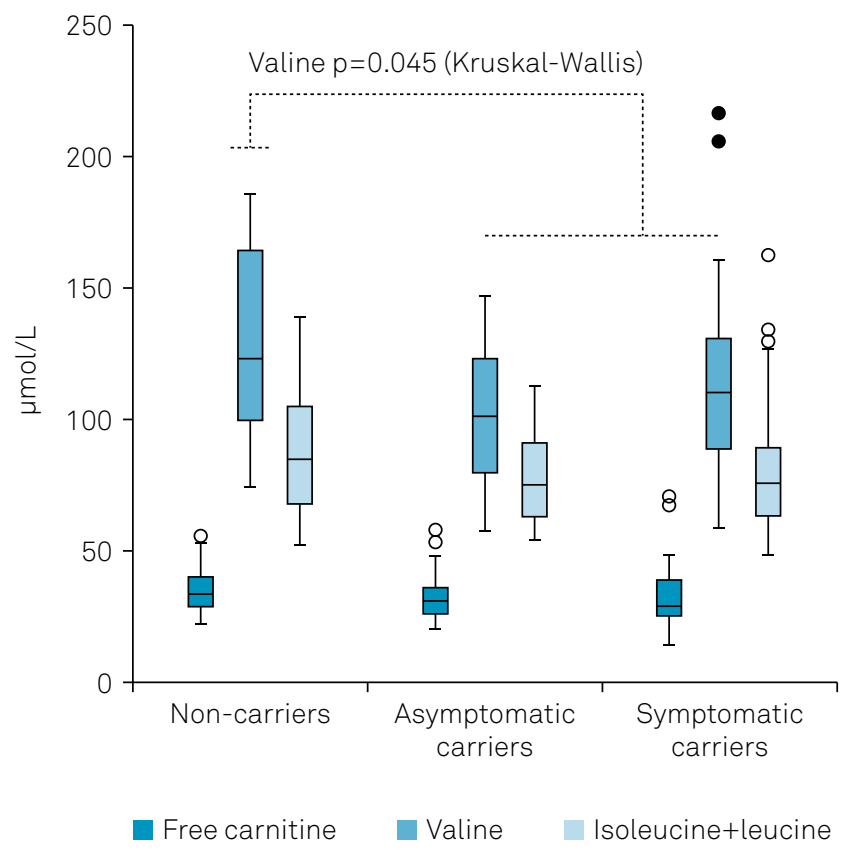

Figure 1. Levels of free carnitine, valine and isoleucine+leucine in non-carriers, asymptomatic, and symptomatic carriers of expanded CAG at HTT.

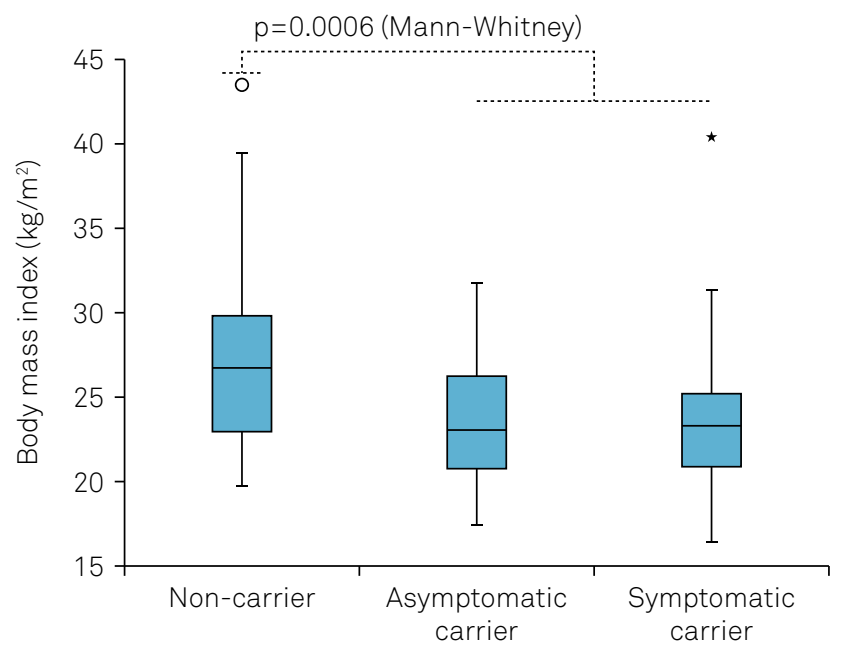

Figure 2. Body mass index distribution among non-carriers, asymptomatic, and symptomatic carriers.
Eight symptomatic HD patients had low levels of free carnitine at baseline (range: 13.9-21.9 $\mu \mathrm{mol} / \mathrm{L}$ ). Their AO was lower $(32.0 \pm 12.7$ vs $42.4 \pm 10.7$ years, $\mathrm{p}=0.028$, t-test) and disease duration was longer $(12.8 \pm 5.7$ vs $8.4 \pm 6.0$ years, $p=0.045$, Mann-Whitney) than symptomatic subjects with normal free carnitine. BMI, expanded CAG tract, CAP score, and all subscales of UHDRS were similar between low and normal free carnitine symptomatic subgroup (ns, t-test and Mann-Whitney).

To clarify whether free carnitine and BCAAs varied according to disease severity, correlations were tested between them and the independent variables under study: CAP score, expanded CAG tract and BMI, in all carriers; and against AO, DD and UHDRS, in symptomatic individuals (Table 2). Associations with free carnitine levels were not found; although valine correlated with $\mathrm{AO}$ ( $\mathrm{rho}=0.315, \mathrm{p}<0.05$; $\mathrm{p}=0.34$ after Bonferroni), with BMI (0.306, $\mathrm{p}<0.05$; $\mathrm{p}=0.55$ after Bonferroni) and isoleucine+leucine correlated with BMI of HD carriers ( $r h o=0.212, p<0.05 ; p=0.66$ after Bonferroni), none was done with measures of disease progression: UHDRS subscales and DD.

Valine and isoleucine+leucine levels were strongly correlated (rho=0.815, $\mathrm{p}<0.0001 ; \mathrm{p}=0.0055$ after Bonferroni). Free carnitine was correlated with isoleucine+leucine (rho=0.261, p<0.025, p=1.3 after Bonferroni), but unrelated to valine (ns, Spearman).

\section{Longitudinal observations}

In 43 symptomatic individuals, a follow-up evaluation was obtained after a median (IQR) interval of 1.1 years (1.0-1.2) (Table 3).

Two scales of clinical severity, UHDRS total motor score and Total Functional Capacity (TFC), were chosen to demonstrate the disease progression within the studied interval. UHDRS total motor score increased by an average of 4.8 points $(\mathrm{p}=0.001$, GEE) and TFC decreased by an average of 0.89 points $(p<0.0001$, GEE) between evaluations (Table 2$)$.

In this time interval, $\mathrm{BMI}(\mathrm{p}=0.52$, GEE) and valine $(\mathrm{p}=0.43$, GEE) remained unchanged. Curiously, significant increases in free carnitine $(p=0.039, \mathrm{GEE})$ and in isoleucine+leucine levels $(p=0.037$, GEE) were registered in the period (Figure 3).

\section{DISCUSSION}

Valine was reduced in HD carriers, for both symptomatic or asymptomatic, whereas isoleucine+leucine and free carnitine were not related to $\mathrm{HD}$ in the present cohort. In a prospective follow-up after one year, while UHDRS motor and functional scores worsened significantly, neither free carnitine nor BCAAs (especially valine) levels changed in symptomatic individuals. In contrast, within the same interval, free carnitine and isoleucine+leucine levels even increased, 
possibly secondary to improvements in the care provided to patients during the study.

Although no clear-cut relationship between BCAAs and HD pathology can be postulated, several reports that evaluated amino acids in the context of a more widespread search for metabolic biomarkers related altered levels of BCAAs to this disorder-9. ${ }^{7-9}$. Reduced levels of BCAAs were found in some $^{7-9}$, but not in other studies ${ }^{11}$. Worth mentioning, longitudinal observations of BCAAs levels on HD were not performed before this present cohort. Our baseline observations indicated that valine levels were reduced in HD carriers, independently from the symptoms status, and showed a trend to correlate with $\mathrm{AO}$ and BMI. Less studied than BCAA in $\mathrm{HD}^{5,11}$, carnitine levels were formerly found to be reduced on advanced stages of disease ${ }^{5}$. Fatty acids are not used for CNS energy generation; a very speculative relationship between this metabolite and HD could be conceived through its role in transporting toxic compounds out of mitochondria. Despite this potential "rationale", we did not find any links between free carnitine and HD characteristics, except in later stages of disease. Even then, free carnitine levels were not

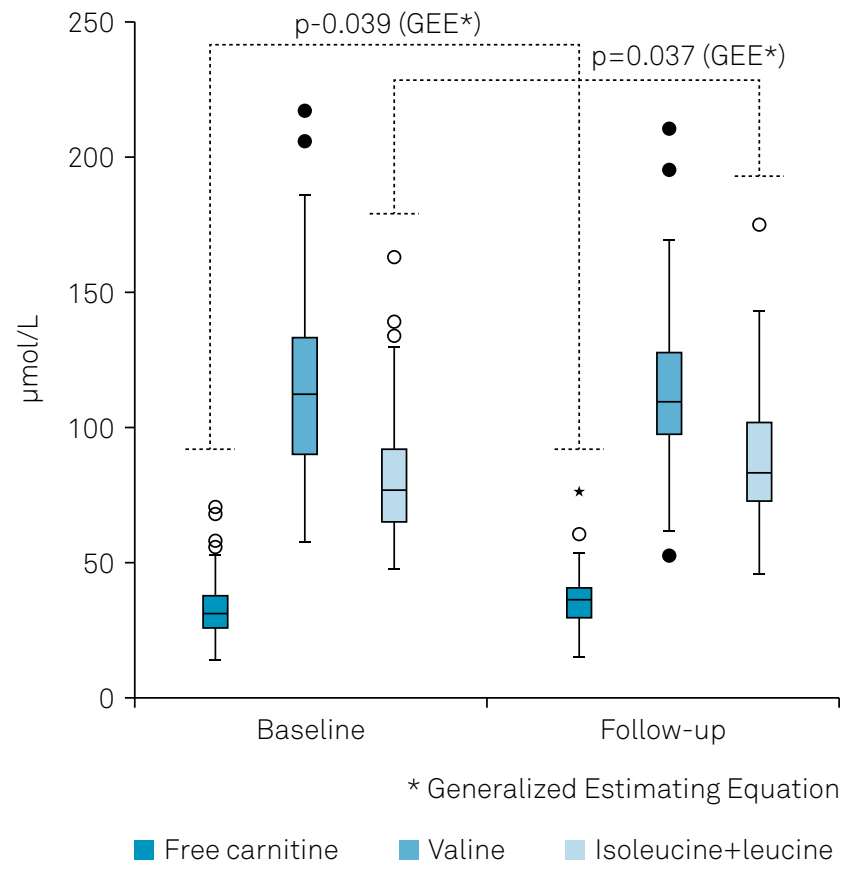

Figure 3. Boxplot of free carnitine, valine and isoleucine+leucine at baseline and follow-up.

Table 2. Associations between the candidate biomarkers free carnitine and BCAAs and independent variables of disease severity at baseline.

\begin{tabular}{|c|c|c|c|c|c|c|}
\hline & & & \multirow{2}{*}{$\begin{array}{c}\text { Free } \\
\text { Carnitine }\end{array}$} & \multicolumn{2}{|c|}{ Branched chain amino acids } & \multirow{2}{*}{$\mathrm{BMI}^{\mathrm{a}}\left(\mathrm{kg} / \mathrm{m}^{2}\right)$} \\
\hline & & & & Valine & Isoleucine+leucine & \\
\hline \multirow{3}{*}{$\begin{array}{l}\text { All expanded CAG } \\
\text { carriers }(n=94)\end{array}$} & & Expanded CAG & ns & ns & ns & ns \\
\hline & & CAP score & ns & ns & ns & ns \\
\hline & & $\mathrm{BMI}(\mathrm{n}=89)$ & ns & ns & $0.212^{*}$ & - \\
\hline \multirow{8}{*}{$\begin{array}{l}\text { Symptomatic } \\
\text { expanded CAG } \\
\text { carriers }(n=74)\end{array}$} & & Age of onset & ns & $0.315^{*}$ & ns & ns \\
\hline & & Disease duration & ns & ns & ns & ns \\
\hline & & $\mathrm{BMI}(\mathrm{n}=70)$ & ns & $0.306 *$ & $0.298 *$ & - \\
\hline & \multirow{5}{*}{ UHDRS } & Total motor score & ns & ns & ns & $-0.376 * *$ \\
\hline & & Total cognition score & ns & ns & ns & $0.427 * *$ \\
\hline & & Functional assessment score & ns & ns & ns & $0.435^{* *}$ \\
\hline & & Independence score & ns & ns & ns & $0.417 * *$ \\
\hline & & Functional capacity & ns & ns & ns & $0.355 * *$ \\
\hline
\end{tabular}

abody mass index (BMI); ${ }^{\star} p<0.05$, Spearman; ${ }^{\star \star} p<0.001$, Spearman; UHDRS: Unified Huntington's Disease Rating Scale.

Table 3. Results observed on BMI, severity scales and free carnitine, valine and isoleucine+leucine on baseline and at 1.08 years of follow-up.

\begin{tabular}{lcccc}
\hline & Baseline $(n=74)$ & Follow-up $(n=43)$ & Mean (standard error of variation) & $p$-value \\
\hline Body mass index $\left(\mathrm{kg} / \mathrm{m}^{2}\right)$ median $(\mathrm{IQR})$ & $23.25(20.85-25.2)$ & $23.9(20.95-26.45)$ & $-0.12(0.36)$ & 0.52 \\
\hline Total motor score mean $(\mathrm{SD})$ & $53(33.75-76.25)$ & $58(36-76)$ & $+4.8(1.55)$ & $-0.89(0.21)$ \\
\hline Total Functional Capacity median $(\mathrm{IQR})$ & $5(2-9)$ & $5(2-8)$ & $+4.15(1.41)$ & 0.001 \\
Free carnitine $(\mu \mathrm{M} / \mathrm{L})$ median $(\mathrm{IQR})$ & $28.7(25.1-38.6)$ & $36.2(28.7-40.2)$ & $+1.8(5.11)$ & 0.039 \\
Valine $(\mu \mathrm{M} / \mathrm{L})$ median $(\mathrm{IQR})$ & $110(88.4-131)$ & $109(95-126)$ & $+7.98(4.08)$ & 0.43 \\
Isoleucine+leucine $(\mu \mathrm{M} / \mathrm{L})$ median $(\mathrm{IQR})$ & $75.6(63.5-89.3)$ & $83.2(72.3-99.2)$ & 0.037 \\
\hline
\end{tabular}

IQR: interquartile range; SD: standard deviation. 
related to expanded CAG tract, DD, CAP score, or severity scales. These cross-sectional findings suggest that carnitine deficiency can be a secondary and late complication, probably non-specific for $\mathrm{HD}$, but common to other long-standing neurodegenerative disorders ${ }^{12}$. Considering carnitine deficiency might be detrimental to metabolite status, it should be screened and treated at least in late stages of HD.

We tested if these candidate biomarkers changed longitudinally after one year. UHDRS and BMI were chosen to be the standard variables to follow disease progression. $\mathrm{BMI}$ has a well-established relationship with $\mathrm{HD}^{8}$, and also due to the fact that it was a way to relate metabolites under study-free carnitine and BCAAs - to a reasonable and acceptable pathophysiological mechanism already associated with HD - energy impairment.

As expected, symptomatic individuals showed a progression of UHDRS total motor score and of TFC; the deterioration observed was similar to those observed in larger cohorts $^{13}$. Just like previous studies have shown, BMI was already reduced in asymptomatic carriers, suggesting that a change in metabolism occurs even before the onset of motor, cognitive, or behavioral symptoms ${ }^{8}$.

BMI and valine did not change significantly among symptomatic individuals after one year, in the prospective observation. This result might suggest that both characteristics are indeed associated, although we were not able to confirm their significance (Table 1). On the other hand, free carnitine and isoleucine+leucine showed increased plasmatic levels in the follow-up assessment. There is no objective reason for this finding, unless an unnoticed improvement in the general care offered to these patients.

Some limitations can be attributed to our study. First, the individuals were fasting for at least 2 hours by the time of blood collection. We know this is not enough and that fast/fed state could interfere with BCAAs and free carnitine levels. According to experiments done by Ottosson et al. ${ }^{14}$, BCAA levels return to fasting levels up to 3 hours after meals, so it is possible that some interference has occurred. A confounding bias related to fast/fed state could potentially induce to errors of interpretation if unbalanced fast/fed states occurred (a) between groups (HD and controls), or (b) between the two evaluations (baseline and follow-up). In the (a) scenario, the group with a higher rate of individuals fed would present higher levels of all BCAA.
Since we only detected reduced levels of one BCAA (valine) in one group, (a) scenario seemed unlikely. In the (b) scenario, differences in fed state between baseline and follow-up evaluations could be responsible for changes in BCAA levels, falsely attributed to disease progression (either reductions or increases). Since we detected an unexpected increase in free carnitine and isoleucine+leucine levels after one year, we cannot rule out that HD symptomatic subjects would be better fed at follow-up. Second, we have performed only one followup assessment in symptomatic carriers, and the observation period might have been too short. A longer period of observation could have detected the velocity of BMI and maybe of valine reduction in HD. However, since none of the candidates was related to DD, it is unlikely that a longer observation period could reveal that free carnitine or BCAAs, especially valine, would be good biomarkers to be used in clinical trials. Third, sample size might had been a problem if a trend to associate one of our candidate biomarkers to UHDRS progression has been raised, but not proved. In fact, we recruited a substantial number of participants, considering the HD families detected in our study centers ${ }^{15}$. Despite that, no trend between biomarkers and disease progression was detected. Fourth, our BCAAs evaluation method did not allow separation of leucine from isoleucine. Nonetheless, previous literature data did not suggest that a potential stability of one amino acid could mask the effect of the other. Finally, a prospective evaluation of the asymptomatic carriers was not carried out. Although lack of differences at baseline between BCAA levels from symptomatic and asymptomatic carriers led us not to expect significant changes in asymptomatic carriers after certain time, there was no other way to prove it than by following these subjects longitudinally.

In conclusion, although plasmatic levels of valine were shown to be lower in HD carriers and potentially related to BMI losses observed even in pre-symptomatic individuals, neither BCAA nor free carnitine were proven to be good biomarkers for HD.

\section{ACKNOWLEDGEMENTS}

The authors would like to thank all families and subjects who participated in this study.

\section{References}

1. MacDonald ME, Ambrose CM, Duyao MP, Myers RH, Lin C, Srinidhi L, et al. The Huntington's Disease Collaborative Research Group. A novel gene containing a trinucleotide repeat that is expanded and unstable on Huntington's disease chromosomes. Cell. 1993 Mar;72(6):971-83. https://doi.org/10.1016/0092-8674(93)90585-e

2. Seong IS, Ivanova E, Lee JM, Choo YS, Fossale E, Anderson M, et al. HD CAG repeat implicates a dominant property of huntingtin in mitochondrial energy metabolism. Hum Mol Genet. 2005 Oct;14(19):2871-80. https://doi.org/10.1093/hmg/ddi319

3. Noland RC, Koves TR, Seiler SE, Lum H, Lust RM, Ilkayeva O, et al. Carnitine insufficiency caused by aging and overnutrition compromises mitochondrial performance and metabolic control.J Biol Chem. 2009 Jun;284(34):22840-52. https://doi.org/10.1074/jbc. M109.032888 
4. Turner C, Schapira AH. Mitochondrial matters of the brain: the role in Huntington's disease. J Bioenerg Biomembr. 2010 Jun;42(3):193-8. https://doi.org/10.1007/s10863-010-9290-y

5. Cuturic M, Abramson RK, Moran RR, Hardin JW, Frank EM, Sellers AA. Serum carnitine levels and levocarnitine supplementation in institutionalized Huntington's disease patients. Neurol Sci. 2013 Jan;34(1):93-8. https://doi.org/10.1007/s10072-012-0952-x

6. Brosnan JT, Brosnan ME. Branched-chain amino acids: enzyme and substrate regulation.J Nutr. 2006 Jan;136(1 Suppl):207S-211S. https://doi.org/10.1093/jn/136.1.207S

7. Underwood BR, Broadhurst D, Dunn WB, Ellis DI, Michell AW Vacher $\mathrm{C}$, et al. Huntington disease patients and transgenic mice have similar pro-catabolic serum metabolite profiles. Brain. 2006 Apr;129(Pt 4):877-86. https://doi.org/10.1093/brain/awl027

8. Mochel F, Charles P, Seguin F, Barritault J, Coussieu C, Perin L, et al. Early energy deficit in Huntington disease: identification of a plasma biomarker traceable during disease progression. PLoS One. 2007 Jul;2(7):e647. https://doi.org/10.1371/journal.pone.0000647

9. Mochel F, Benaich S, Rabier D, Durr A. Validation of plasma branched chain amino acids as biomarkers in Huntington disease. Arch Neurol. 2011 Feb;68(2):265-7. https://doi.org/10.1001/archneurol.2010.358

10. Castilhos RM, Souza AF, Furtado GV, Gheno TC, Silva AL, Vargas FR, et al. Huntington disease and Huntington disease-like in a case series from Brazil. Clin Genet. 2014 Oct;86(4):373-7. https://doi.org/10.1111/ cge.12283

11. Mastrokolias A, Pool R, Mina E, Hettne KM, van Duijn E, van der Mast $\mathrm{RC}$, et al. Integration of targeted metabolomics and transcriptomics identifies deregulation of phosphatidylcholine metabolism in Huntington's disease peripheral blood samples. Metabolomics. 2016 Aug;12:137. https://doi.org/10.1007/s11306-016-1084-8

12. Virmani A, Pinto L, Bauermann O, Zerelli S, Diedenhofen A, Binienda ZK, et al. The Carnitine Palmitoyl Transferase (CPT) system and possible relevance for neuropsychiatric and neurological conditions. Mol Neurobiol. 2015 Oct;52(2):826-36. https://doi.org/10.1007/s12035-015-9238-7

13. Dorsey ER, Beck CA, Darwin K, Nichols P, Brocht AF, Biglan KM, et al. Natural history of Huntington disease. JAMA Neurol. 2013 Dec;70(12):1520-30

14. Ottosson F, Ericson U, Almgren P, Nilsson J, Magnusson M, Fernandez $C$, et al. Postprandial levels of branch chained and aromatic amino acids associate with fasting glycaemia. J Amino Acids. 2016;8576730:1-9. https://doi.org/10.1155/2016/8576730

15. Castilhos RM, dos Santos JA, Augustin MC, Pedroso JL, Barsottini $\mathrm{O}$, Saba R, et al. Minimal Prevalence of Huntington's disease in South Brazil and instability of the expanded CAG tract during intergenerational transmissions. Genet Mol Biol. 2019 AprJun;42(2):329-36. https://doi.org/10.1590/1678-4685-GMB-2018-003 